\title{
Differentiation of phase I and variant strains of Bordetella pertussis on Congo red media
}

\section{R. PARTON} Department of Microbiology, University of Glasgow, Alexander Stone Building, Garscube Estate, Bearsden,
Glasgow G61 10H

\begin{abstract}
Summary. The addition of Congo red, Trypan blue or haemin to the growth medium allowed the differentiation of phase-I and variant strains of Bordetella pertussis. Phase-I strains produced red $\left(\mathrm{CR}^{+}\right)$, blue or dark brown colonies on a modified cyclodextrin solid medium containing Congo red, Trypan blue or haemin, respectively, whereas variant $\left(\mathrm{Vir}^{-}\right.$and phase IV) strains grew as pale $\left(\mathrm{CR}^{-}\right)$colonies. Spontaneous $\mathrm{CR}^{-}$variants were isolated and characterised and had a phenotype like that of $\mathrm{Vir}^{-}$ or phenotypically modulated, C-mode strains in that they did not produce the haemolysin, haemagglutinin(s), histamine-sensitising factor (pertussis toxin), heatlabile toxin and two major envelope polypeptides associated with phase-I strains. Two such variants had reduced virulence for mice. $\mathrm{CR}^{+}$strains, when grown on a high nicotinic acid medium to induce modulation, gave $\mathrm{CR}^{-}$colonies. Thus the $\mathrm{CR}^{+}$ phenotype is a characteristic of phase-I $B$. pertussis and its expression appears to be controlled in a manner similar to that of other phase I-related factors. $\mathrm{CR}^{-}$variants of $B$. parapertussis and $B$. bronchiseptica were also deficient in these factors. Four isolates of $B$. avium were $\mathrm{CR}^{-}$
\end{abstract}

\section{Introduction}

With several bacterial species, it is possible to identify variant strains by their inability to bind certain dyes such as Congo red. Payne and Finkelstein (1977) found that strains of Shigella, Vibrio cholerae, Escherichia coli and Neisseria meningitidis grown on Congo red agar normally produced red $\left(\mathrm{CR}^{+}\right)$colonies. Variants that failed to absorb the dye produced colourless $\left(\mathrm{CR}^{-}\right)$colonies and had reduced virulence in a chick embryo model. Trypan blue, a bis-azo dye similar to Congo red, was absorbed by $\mathrm{CR}^{+}$but not by $\mathrm{CR}^{-}$strains.

Similar findings have been made with other species. $\mathrm{CR}^{+}$and $\mathrm{CR}^{-}$variants of a large number of strains of Yersinia enterocolitica and related species were tested for virulence in a mouse model and only $\mathrm{CR}^{+}$strains were virulent (Prpic et al., 1983, 1985). A correlation between Congo red binding and haemin binding by Yersinia spp. has also been noted (Surgalla and Beesley, 1969; Prpic et al., 1985; Robins-Browne et al., 1986). In $S$. flexneri, loss of the ability to bind Congo red was accompanied by loss of ability to invade epithelial cells in culture (Maurelli et al., 1984). Congo red agar has also been used to select strains of the fish

Received 22 June 1987; revised version accepted 5 Jan 1988. pathogen Aeromonas salmonicida possessing a surface protein layer that is absolutely required for virulence (Ishiguro et al., 1985). More recently, a direct correlation was noted between the ability of $E$. coli isolates to form $\mathrm{CR}^{+}$colonies and their ability to cause septicaemic infections in chickens (Berkhoff and Vinal, 1986).

This simple visual test, the ability of bacterial colonies to absorb Congo red, Trypan blue or haemin from the growth medium, has been applied to strains of Bordetella pertussis and other Bordetella spp. for the differentiation of phase-I and variant strains. Phase-I (X-mode) strains of $B$. pertussis normally possess a characteristic range of properties, including production of haemolysin, heatlabile toxin, haemagglutinin(s), histamine-sensitising factor (pertussis toxin) and certain envelope polypeptides, and mouse-virulence, that are absent in genotypic (phase IV) and phenotypic (C-mode) variants (Robinson et al., 1986). Weiss et al. (1983) introduced the terms "virulent phase" $\left(\mathrm{Vir}^{+}\right.$phenotype) and "avirulent phase" (Vir" phenotype) as a concise description of strains with or without this usual range of (phase I-related) properties. It must be stressed however that such terminology does not necessarily reflect the behaviour of the strains in experimental infections (Weiss et al., 1983) or in man. 


\section{Materials and methods}

\section{Bacterial strains}

The following strains were used: $B$. pertussis phase I ( 5 strains), 18-323 (NCTC 10739), L84I (NCTC 11089), 18334 , 165, Tohama; B. pertussis phase IV (2 strains), L84IV (NCTC 10901) and 11615; B. parapertussis (2 strains), NCTC 10520 and NCTC 5952; B. bronchiseptica (2 strains), 214 and 5376. Transposon-insertion mutants of B. pertussis (Weiss et al., 1983) were provided by Dr A. Weiss, Microbiology and Immunology Department, Medical College of Virginia, Richmond VA, USA. These were: BP348 $\left(\mathrm{Adc}^{-}, \mathrm{Hly}^{-}\right.$, adenylate cyclase- and haemolysin-deficient); BP349 $\left(\mathrm{Hly}^{-}\right)$; BP353 (Fha ${ }^{-}$, deficient in filamentous haemagglutinin); BP357 ( $\mathrm{Ptx}^{-}$, deficient in pertussis toxin); BP347 ( Vir $^{-}$, deficient in adenylate cyclase, haemolysin, pertussis toxin, filamentous haemagglutinin and heat-labile toxin).

B. avium strains P-4084, P-4091, P-4148, P-4480 (Rimler and Simmons, 1983) were provided by Dr R.B. Rimler, National Animal Diseases Center, Ames, Iowa, USA.

\section{Media}

Bordet-Gengou (BG) plates were used for routine growth of Bordetella spp. and for assessment of haemolytic activity. The plates consisted of a thick layer of BG Agar Base (Gibco) with a thin overlay of BG agar base containing defibrinated horse blood $20 \% \mathrm{v} / \mathrm{v}$.

Cyclodextrin solid medium (CSM) was a modification of the medium of Imaizumi et al. (1983) and contained (/L) monosodium glutamate $10.7 \mathrm{~g}$, L-proline $0.24 \mathrm{~g}$, $\mathrm{NaCl} 2.5 \mathrm{~g}, \mathrm{KH}_{2} \mathrm{PO}_{4} 0.5 \mathrm{~g}, \mathrm{KCl} 0.2 \mathrm{~g}, \mathrm{MgCl}_{2} .6 \mathrm{H}_{2} 00.1 \mathrm{~g}$, $\mathrm{CaCl}_{2} 0.02 \mathrm{~g}$, Tris $6.1 \mathrm{~g}$, casein hydrolysate peptone 5 (Gibco) $0.5 \mathrm{~g}, 2,6-0$-dimethyl $\beta$-cyclodextrin (Me $\beta C D$ ) $1.0 \mathrm{~g}$ and Bacto-Agar (Difco) $18 \mathrm{~g}$, in distilled water. It was adjusted to $p \mathrm{H} 7.4$ then autoclaved at $121^{\circ} \mathrm{C}$ for $15 \mathrm{~min}$. A supplement containing L-cysteine $0.04 \mathrm{~g}$, $\mathrm{FeSO}_{4} .7 \mathrm{H}_{2} 00.1 \mathrm{~g}$, ascorbic acid $0.02 \mathrm{~g}$, nicotinic acid $0.004 \mathrm{~g}$, and reduced glutathione $0.15 \mathrm{~g}$ in $10 \mathrm{ml}$ of distilled water was sterilised by membrane filtration and added to each litre of basal medium. This modified medium contained ten times more $\mathrm{FeSO}_{4}$ than in the original formulation which, in our hands, supported the growth of $<1 \%$ of the colonies detected on $B G$ medium. With the increased $\mathrm{FeSO}_{4}$, the plating efficiency was similar to that on BG. Me $\beta C D$ was kindly provided by Dr J. Shimizu, Teijin Ltd, Chiyoda-ku, Tokyo, Japan.

A high nicotinic acid medium was used for growth of phenotypically altered C-mode cells (Pusztai and Joó, 1967; Wardlaw et al., 1976; Schneider and Parker, 1982). Nicotinic acid was dissolved in a small amount of $1 \mathrm{~N}$ $\mathrm{NaOH}$, made up to $10 \mathrm{mg} / \mathrm{ml}$ with distilled water, sterilised by membrane filtration, and $5 \mathrm{ml}$ was added to each $100 \mathrm{ml}$ of CSM.

The differential media were prepared by adding Congo red, Trypan blue or haemin to CSM or to both layers of the BG medium. Haemin was dissolved in $1 \mathrm{~N} \mathrm{NaOH}$ and stock solutions $(1 \% \mathrm{w} / \mathrm{v})$ of all three reagents were sterilised by autoclaving and added to the molten agar in the required amounts.

Plates were incubated in a moist atmosphere at $37^{\circ} \mathrm{C}$ for up to 7 days.

\section{Characterisation of strains}

Haemolysin production was assessed after growth on BG plates.

Haemagglutinin(s). Growth from the solid media was suspended in phosphate buffered saline (PBS), $p \mathrm{H} 7 \cdot 2$, to a concentration of 10 opacity units $(\mathrm{OU})$ by comparison with the WHO 5th International Reference Preparation of Opacity (Perkins et al., 1973); 50- $\mu$ l amounts were added to equal volumes of thrice-washed horse red blood cells $(2 \% \mathrm{v} / \mathrm{v}$ in PBS) in U-shaped wells of plastic microtitration trays. After mixing, the trays were left at room temperature for $2 \mathrm{~h}$ before haemagglutination was assessed. Although $B$. pertussis contains at least two haemagglutinins, pertussis toxin and filamentous haemagglutinin (FHA), this test appears to measure only FHA since the mutant strain BP353 $\left(\mathrm{Fha}^{-}, \mathrm{Ptx}^{+}\right)$gave a negative result.

Histamine-sensitising factor (pertussis toxin). The bacterial suspensions ( $10 \mathrm{OU}$ ) prepared above were heated at $56^{\circ} \mathrm{C}$ for $30 \mathrm{~min}$ to destroy heat-labile toxin, and 0.5 $\mathrm{ml}$ amounts were injected intraperitoneally (i.p.) into groups of five adult HaM/ICR mice. After 5 days the animals were challenged i.p. with $0.5 \mathrm{ml}$ of saline containing $3 \mathrm{mg}$ of histamine dihydrochloride and survivors were counted after $3 \mathrm{~h}$. This challenge dose of bacteria gave a clear distinction between phase-I $B$. pertussis (no survivors) and phase-IV and C-mode cells (all survived).

Heat-labile toxin activity was determined by skin reactions after subcutaneous injection of 3-4-week-old mice (Parton, 1986). Mice received injections of 0.05-ml amounts of the bacterial suspensions diluted to $2 \mathrm{OU}$ in PBS. A reaction of $>5 \mathrm{~mm}$ in diameter was taken as a positive response.

Virulence for mice by the intranasal route of infection was determined by the method of Pittman et al. (1980) with 3-week-old HaM/ICR mice.

$X$-bands. The presence of two major phase I (X-mode)specific envelope proteins (X-bands) of mol. wt. c. 30000 was determined by sodium dodecyl sulphate-polyacrylamide gel electrophoresis (SDS-PAGE) of whole-cell suspensions (Brownlie et al., 1985). A comparison of the protein profiles also served to confirm the identity of the isolates as Bordetella strains.

Growth on nutrient agar was assessed with thick plates of Nutrient Agar (Oxoid) incubated as described above.

\section{Results}

All of the phase-I B. pertussis strains gave red $\left(\mathrm{CR}^{+}\right)$colonies when stock cultures were streaked on to modified CSM containing Congo red $0.002 \% \mathrm{w} / \mathrm{v}$ (CSM-CR), whereas two phase-IV 
strains gave pale $\left(\mathrm{CR}^{-}\right)$colonies. The transposoninsertion mutants of Weiss et al. (1983), BP348 $\left(\mathrm{Adc}^{-}, \mathrm{Hly}^{-}\right), \mathrm{BP} 349\left(\mathrm{Hly}^{-}\right), \mathrm{BP} 353\left(\mathrm{Fha}^{-}\right)$and BP357 $\left(\mathrm{Ptx}^{-}\right)$, all produced $\mathrm{CR}^{+}$colonies. However, BP347 $\left(\mathrm{Vir}^{-}\right)$, deficient in a number of phase I-related properties, had the $\mathrm{CR}^{-}$phenotype. The two $B$. parapertussis and two $B$. bronchiseptica strains tested were $\mathrm{CR}^{+}$whereas all four $B$. avium strains were $\mathrm{CR}^{-}$.

With some of the $\mathrm{CR}^{+}$strains, pale colonies were sometimes seen amongst the predominantly red colonies. These $\mathrm{CR}^{-}$variants were subcultured on the same medium and tested for characteristics normally associated with phase-I $B$. pertussis strains and absent in BP347 and phase-IV strains (table). One $\mathrm{CR}^{-}$variant from each of strains L84I, 165, 18334 and BP348 was fully characterised and they all had an identical phenotype. They lacked haemagglutinating activity, histamine-sensitising factor (pertussis toxin), heat-labile toxin and two major envelope proteins ( $\mathrm{X}$-bands) associated with phase-I (or X-mode) strains. They were nonhaemolytic on BG medium and did not readily grow to single colonies on nutrient agar. Thus, they resembled BP347 and differed from phase-IV strains only in the last-mentioned characteristic. However, with the $\mathrm{CR}^{-}$isolates and BP347, it was possible to obtain the growth of a few, isolated colonies by streaking a heavy inoculum on to nutrient agar. This was never seen with phase-I strains. Several other $\mathrm{CR}^{-}$clones were isolated from these same $B$. pertussis strains and all lacked haemolysin and haemagglutinin but these strains have not been characterised further.

The lack of phase I-related factors in the $\mathrm{CR}^{-}$ isolates was paralleled by loss of virulence for mice by the intranasal route. The $\mathrm{CR}^{-}$variants of $B$. pertussis L84I and 165 caused no deaths in 3-weekold mice even at the highest dose tested (LD50 > $10^{8} \mathrm{cfu} /$ mouse) whereas the LD50 values for the parent $\mathrm{CR}^{+}$strains were $<10^{7} \mathrm{cfu} /$ mouse.

When phase-I (X-mode) B. pertussis strains L84I, 165 and 18334 were grown on CSM-CR containing a high concentration of nicotinic acid $(500 \mu \mathrm{g} / \mathrm{ml})$ to induce phenotypically altered $\mathrm{C}$-mode cells, all of the resulting colonies were $\mathrm{CR}^{-}$. The $\mathrm{C}$-mode state of these cultures was confirmed by the absence of haemagglutinating activity, heat-labile toxicity and $\mathrm{X}$-bands in cell suspensions (table).

A spontaneous $\mathrm{CR}^{-}$variant was isolated from each of the $B$. parapertussis and $B$. bronchiseptica strains and, where tested, the variants were shown to lack certain characteristics of the parents, namely haemolysin production, haemagglutinating activity and heat-labile toxin (table). As with $B$. pertussis strains, when grown on the high nicotinic acid

Table. Congo red phenotype and other characteristics of various Bordetella strains

\begin{tabular}{|c|c|c|c|c|c|c|c|c|}
\hline \multirow[b]{2}{*}{$\begin{array}{c}\text { Species and strains } \\
\text { (number of strains } \\
\text { tested) }\end{array}$} & \multirow[b]{2}{*}{$\begin{array}{l}\text { Congo } \\
\text { red bind- } \\
\text { ing }\end{array}$} & \multicolumn{4}{|c|}{ Production of } & \multirow[b]{2}{*}{$\begin{array}{c}\text { Presence } \\
\text { of } \\
\text { X-bands } \\
\text { in SDS-PAGE }\end{array}$} & \multirow[b]{2}{*}{$\begin{array}{c}\text { Growth on } \\
\text { nutrient } \\
\text { agar }\end{array}$} & \multirow[b]{2}{*}{$\begin{array}{l}\text { Mouse- } \\
\text { virulence* } \\
\text { (LD50) }\end{array}$} \\
\hline & & Haemolysin & $\begin{array}{l}\text { Haemagglu- } \\
\text { tinin(s) }\end{array}$ & $\begin{array}{l}\text { Histamine- } \\
\text { sensitising } \\
\text { factor }\end{array}$ & $\begin{array}{l}\text { Heat- } \\
\text { labile } \\
\text { toxin }\end{array}$ & & & \\
\hline \multicolumn{9}{|l|}{ B. pertussis } \\
\hline phase I (5) & $\mathrm{CR}^{+}$ & + & + & + & + & + & - & $<10^{7} \mathrm{cfu} /$ mouse \\
\hline phase IV (2) & $\mathrm{CR}^{-}$ & - & - & - & - & - & + & $\ldots$ \\
\hline BP347 $\left(\mathrm{Vir}^{-}\right)$ & $\mathrm{CR}^{-}$ & - & - & - & - & - & - & $\ldots$ \\
\hline $\begin{array}{l}\text { spontaneous } \mathrm{CR}^{-} \\
\text {variant (4) }\end{array}$ & $\mathrm{CR}^{-}$ & - & - & - & - & - & - & $>10^{8} \mathrm{cfu} /$ mouse \\
\hline $\begin{array}{l}\text { phase I grown on } \\
\text { high nicotinic } \\
\text { acid medium (5) }\end{array}$ & $\mathrm{CR}^{-}$ & $\ldots$ & - & $\ldots$ & - & - & $\ldots$ & $\ldots$ \\
\hline $\begin{array}{l}\text { B. parapertussis } \\
\text { parent (2) }\end{array}$ & $\mathrm{CR}^{+}$ & + & + & $\ldots$ & + & $\cdots$ & + & $\ldots$ \\
\hline $\begin{array}{l}\text { spontaneous } \mathrm{CR}^{-} \\
\text {variant }(2)\end{array}$ & $\mathrm{CR}^{-}$ & - & - & $\cdots$ & - & $\cdots$ & + & $\cdots$ \\
\hline \multicolumn{9}{|l|}{ B. bronchiseptica } \\
\hline parent (2) & $\mathrm{CR}^{+}$ & + & + & $\ldots$ & $\ldots$ & $\ldots$ & + & $\ldots$ \\
\hline $\begin{array}{l}\text { spontaneous } \mathrm{CR}^{-} \\
\text {variant (2) }\end{array}$ & $\mathrm{CR}^{-}$ & - & - & $\cdots$ & $\cdots$ & $\cdots$ & + & $\cdots$ \\
\hline
\end{tabular}

$\ldots$, not tested or not applicable.

* Only two phase I strains, L84I and 165 , and their $\mathrm{CR}^{-}$variants were tested. 
medium, the $\mathrm{CR}^{+}$strains produced $\mathrm{CR}^{-}$colonies which were non-haemagglutinating.

$\mathrm{CR}^{+}$and $\mathrm{CR}^{-}$colonies could also be differentiated by replacing the Congo red in CSM with Trypan blue $0.002 \% \mathrm{w} / \mathrm{v}$, in which case blue or pale colonies respectively were produced, or with hae$\min (0.005 \% \mathrm{w} / \mathrm{v})$ when dark brown or pale colonies were produced. However, the distinction between the two types was not as marked with haemin as with the dyes. It was also possible to use BG medium, instead of CSM, to observe dye binding. This was achieved by incorporating a higher concentration of the dye $(0.01 \% \mathrm{w} / \mathrm{v})$ in the growth medium, applying membrane filters (Whatman, cellulose nitrate, $0.45 \mu \mathrm{m}$ ) to the surface of the medium and streaking out across the membrane. After incubation, the red, blue or pale colonies were readily distinguished against the light background of the filter. Some component of BG medium appeared to interfere with haemin binding since even with the addition of haemin $0.01 \% \mathrm{w} / \mathrm{v}$ to the agar, $\mathrm{CR}^{+}$strains grew as pale colonies on the membrane. It should be noted that with prolonged storage at room temperature or in the refrigerator, the $\mathrm{CR}^{-}$strains began to take up the dyes and the difference between $\mathrm{CR}^{+}$and $\mathrm{CR}^{-}$became less apparent.

\section{Discussion}

$B$. pertussis resembles certain other bacterial species in that parent and variant strains can be differentiated by their ability to take up Congo red, Trypan blue or haemin from the growth medium. Phase-I $B$. pertussis strains had this ability. The phase-IV strains (Leslie and Gardner, 1931 ; Robinson et al., 1986), the so-called avirulent-phase (Vir ${ }^{-}$) mutant BP347 (Weiss et al., 1984), and the phenotypically altered C-mode cells (Lacey, 1960) lacked the ability, and these strains are known to be less virulent for mice than their parents. Moreover, spontaneous $\mathrm{CR}^{-}$strains lacked the usual range of factors possessed by phase-I strains, namely production of haemolysin, heat-labile toxin, haemagglutinin(s), histamine-sensitising factor and two major envelope polypeptides, and two such strains were shown to be avirulent for mice.

The spontaneous $\mathrm{CR}^{-}$variants of $B$. pertussis appear to be similar to the avirulent-phase $\left(\mathrm{Vir}^{-}\right)$ variants described by Weiss and Falkow (1984) and to variants isolated by Peppler (1982) and Goldman et al. (1984) and are distinct from the classical phase-IV strains which grow readily on nutrient agar (Robinson et al., 1986). They are presumed to have accumulated within the stock cultures of the parent strains before streaking onto CSM-CR. No reversion of these strains to the $\mathrm{CR}^{+}$phenotype has been observed. The concomitant loss of several phase I-related factors along with the Congo red phenotype in these isolates, in strain BP347, in phase-IV strains and under C-mode conditions (Parton and Wardlaw, 1975; Wardlaw et al., 1976), suggests that a common regulatory mechanism is involved. Weiss and Falkow (1984) have proposed that a trans-acting positive effector, the product of the vir gene, is responsible for the expression of many of the putative virulence factors of $B$.pertussis. Inactivation of this gene by mutation or, as in BP347, by a single transposon Tn5 insertion, or in $\mathrm{C}$-mode cells by environmental signals such as nicotinic acid, prevents expression of the putative virulence-associated genes. Thus the $\mathrm{CR}^{+}$phenotype appears to be yet another characteristic whose expression is controlled by the vir gene.

A similar concomitant loss of activities and Congo red binding was observed in variants of $B$. parapertussis and $B$. bronchiseptica and under $C$ mode conditions suggesting that these closelyrelated species also have a functional vir gene. The recently described $B$. avium (Kersters et al., 1984), the causative agent of turkey coryza, appears to be more distantly related and all four strains tested were $\mathrm{CR}^{-}$. Moreover, although the organism produces a heat-labile toxin similar in activity to that of the other Bordetella species, expression of the toxin was not affected by growth in the high nicotinic acid medium (unpublished observations). It may be that this species does not have the same regulatory mechanisms as the other Bordetella species.

The virulence of $\mathrm{CR}^{-}$variants of Shigella, $\mathrm{V}$. cholerae, $E$. coli and $N$. meningitidis, in a chick embryo model, was restored by supplementation with iron, suggesting that the variants were defective in their ability to acquire iron in vivo (Payne and Finkelstein, 1977). Pathogenic organisms growing in the iron-restricted environment in vivo have developed mechanisms for assimilating proteinbound iron or for acquiring it from cell-free haem (Griffiths, 1983). The correlation between Congo red binding and haemin binding has been noted previously (Surgalla and Beesley, 1969; Prpic et al., 1985 ) and the binding sites may be identical (Kay et al., 1985; Daskaleros and Payne, 1987). Haemin and the related compound protoporphyrin IX were strong competitive inhibitors of Congo red binding to $\mathrm{CR}^{+}$cells of $A$. salmonicida, presumably due to their structural similarity to the dye (Kay et al., 1985). One possible function suggested for the Congo red binding site is to use protoporphyrin IX 
(haemin without the ferric ion ligand) to strip iron from host iron-binding proteins. It is interesting to note that $B$. pertussis also may obtain its iron directly from host iron-binding proteins (Redhead et al., 1987). With $\mathrm{CR}^{+}$strains of $S$. flexneri, haemin binding and haemin uptake were independent since both $\mathrm{CR}^{+}$and $\mathrm{CR}^{-}$strains could use haemin as the sole source of iron. However, in $\mathrm{CR}^{+}$ strains, pre-treatment with haemin enhanced invasiveness for HeLa cells and it was suggested that this binding ability was in some way involved in attachment to host cells (Daskaleros and Payne, 1987).

Congo red binds to $A$. salmonicida by two different mechanisms; one is specific and of high affinity and the other is non-specific and probably due to hydrophobic interactions (Kay et al., 1985). The surface of phase-I $\left(\mathrm{CR}^{+}\right) B$. pertussis cells is known to be hydrophobic whereas that of $\mathrm{C}$-mode and phase variant strains is hydrophilic (Robinson et al., 1983; Fish et al., 1987). It is possible that differences in Congo red binding in $B$. pertussis are simply a reflection of differences in cell-surface hydrophobicity. Fish et al. (1987) suggested that filamentous haemagglutinin (FHA) is the main hydrophobic constituent of the cell, but it cannot be the only Congo red binding site since strain BP353, the FHA-deficient mutant of Weiss et al. (1983), gave $\mathrm{CR}^{+}$colonies, as did the other mutants deficient in only one or two of the phase I-related factors. Differences in Congo red binding due to the presence or absence of different surface components in variant strains could possibly be dem-

\section{REFERENCES}

Berkhoff, H A, Vinal A C 1986 Congo red medium to distinguish between invasive and non-invasive Escherichia coli pathogenic for poultry. Avian Diseases $30: 117-121$.

Brownlie R M, Parton R, Coote J G 1985 The effect of growth conditions on adenylate cyclase activity and virulencerelated properties of Bordetella pertussis. Journal of General Microbiology 131 : 17-25.

Carter E J, Preston N W 1981 Pulmonary pertussis infection in the mouse: no solution to an old problem. Journal of Infection 3: 86-88.

Coote J G, Brownlie R M 1988 Genetics of virulence of Bordetella pertussis. In: Wardlaw A C, Parton R (eds) Pathogenesis and immunity in pertussis. John Wiley and Sons Ltd, Chichester, in press.

Fish F, Navon Y, Goldman S 1987 Hydrophobic adherence and phase variation in Bordetella pertussis. Medical Microbiology and Immunology 176: 37-46.

Daskaleros P A, Payne S M 1987 Congo red binding phenotype is associated with hemin binding and increased infectivity of Shigella flexneri in the HeLa cell model. Infection and Immunity 55: 1393-1398.

Goldman S, Hanski E, Fish F 1984 Spontaneous phase variation onstrated by the quantitative dye-binding assay of Payne and Finkelstein (1977).

Clearly, the relationship between Congo red binding, iron acquisition, attachment and mousevirulence in $B$. pertussis requires further investigation. We are currently trying to isolate, by chemical or transposon mutagenesis, $\mathrm{CR}^{-}$variants of $B$. pertussis that have the full complement of other phase-I-related factors, in order to assess the significance of Congo red binding for mousevirulence. Transposon mutagenesis has already been used to show the importance of pertussis toxin and adenylate cyclase in the mouse model (Weiss et al., 1984). The Congo red phenotype may also be useful in studying the frequency of variation from the "virulent phase" to the "avirulent phase" as defined by Weiss et al. (1983) and the reversibility of the process (Weiss and Falkow, 1984). It must be borne in mind, however, that virulence of $B$. pertussis strains for mice cannot be equated with their virulence for man (Carter and Preston, 1981). The pathogenesis of whooping cough is complex and the contribution of the various phase-I-related factors remains speculative (Wardlaw and Parton, 1988). The screening of compounds for their modulating effect on $B$. pertussis, and the occurrence of variant strains during pertussis infection (reviewed by Coote and Brownlie, 1988) are other possible areas of investigation.

I thank Dr J. G. Coote and Professor A.C. Wardlaw for helpful discussions.

in Bordetella pertussis is a multistep non-random process. The EMBO Journal 3:1353-1356.

Griffiths E 1983 Adaptation and multiplication of bacteria in host tissues. Philosophical Transactions of the Royal Society of London 303 series B: 85-96.

Imaizumi A, Suzuki Y, Ono S, Sato H, Sato Y 1983 Heptakis (2, 6-O-dimethyl) B-cyclodextrin : a novel growth stimulant for Bordetella pertussis phase I. Journal of Clinical Microbiology 17:781-786.

Ishiguro E E, Ainsworth T, Trust T J, Kay W W 1985 Congo red agar, a differential medium for Aeromonas salmonicida detects the presence of the cell surface protein array involved in virulence. Journal of Bacteriology 164: 12331237.

Kay W W, Phipps B M, Ishiguro E E, Trust T J 1985 Porphyrin binding by the surface array virulence protein of Aeromonas salmonicida. Journal of Bacteriology 164:1332-1336.

Kersters K et al. 1984 Bordetella avium sp. nov., isolated from the respiratory tracts of turkeys and other birds. International Journal of Systematic Bacteriology 34: 56-70.

Lacey B W 1960 Antigenic modulation of Bordetella pertussis. Journal of Hygiene 58: 57-93.

Leslie P H, Gardner A D 1931 The phases of Haemophilus pertussis. Journal of Hygiene 31 : 423-434. 
Maurelli A T, Blackmon B, Curtiss R 1984 Loss of pigmentation in Shigella flexneri 2a is correlated with loss of virulence and virulence-associated plasmid. Infection and Immunity 43: 397-401.

Parton R 1986 Effect of anti-inflammatory agents on the haemorrhagic response of mouse skin to Bordetella pertussis heat-labile toxin. Journal of Medical Microbiology 21 :265270.

Parton R, Wardlaw A C 1975 Cell-envelope proteins of Bordetella pertussis. Journal of Medical Microbiology 8:47-57.

Payne S M, Finkelstein R A 1977 Detection and differentiation of iron-responsive avirulent mutants on Congo red agar. Infection and Immunity 18:94-98.

Peppler M S 1982 Isolation and characterization of isogenic pairs of domed hemolytic and fiat nonhemolytic colony types of Bordetella pertussis. Infection and Immunity 35: 840851.

Perkins F T, Sheffield F W, Outschoorn A G, Hemsley D A 1973 An international collaborative study on the measurement of the opacity of bacterial suspensions. Journal of Biological Standardization $1: 1-10$.

Pittman M, Furman B L, Wardlaw A C 1980 Bordetella pertussis respiratory tract infection in the mouse : pathophysiological responses. The Journal of Infectious Diseases 142:56-66.

Prpic J K, Robins-Browne R M, Davey R B 1983 Differentiation between virulent and avirulent Yersinia enterocolitica isolates by using Congo red agar. Journal of Clinical Microbiology 18:486-490.

Prpic J K, Robins-Browne R M, Davey R B 1985 In vitro assessment of virulence in Yersinia enterocolitica and related species. Journal of Clinical Microbiology 22: 105-110.

Pusztai Z, Joó I 1967 Influence of nicotinic acid on the antigenic structure of Bordetella pertussis. Annals Immunologiae Hungaricae 10:63-67.

Redhead K, Hill T, Chart H 1987 Interaction of lactoferrin and transferrins with the outer membrane of Bordetella pertussis. Journal of General Microbiology 133:891-898.
Rimler R B, Simmons D G 1983 Differentiation among bacteria isolated from turkeys with coryza (rhinotracheitis). Avian Diseases 27:491-500.

Robins-Browne R M, Prpic J K, Davey R B 1986 Influence of the virulence plasmid and the Congo red reaction on the antimicrobial susceptibility of Yersinia species. Journal of Antimicrobial Chemotherapy 17:553-557.

Robinson A, Duggleby C J, Gorringe A R, Livey I 1986 Antigenic variation in Bordetella pertussis. In: Birkbeck $\mathrm{T}$ $H$, Penn $C W$ (eds) Antigenic variation in infectiaus diseases. IRL Press, Oxford, pp 147-161.

Robinson A, Gorringe A R, Irons L I, Keevil C W 1983 Antigenic modulation of Bordetella pertussis in continuous culture. FEMS Microbiology Letters 19:105-109.

Schneider D R, Parker C D 1982 Effect of pyridines on phenotypic properties of Bordetella pertussis. Infection and Immunity 38: 548-553.

Surgalla M J, Beesley E D 1969 Congo red-agar plating medium for detecting pigmentation in Pasteurella pestis. Applied Microbiology 18:834-837.

Wardlaw A C, Parton R 1988 The host-parasite relationship in pertussis. In: Wardlaw A C, Parton R (eds) Pathogenesis and immunity in pertussis. John Wiley and Sons Ltd, Chichester, in press.

Wardlaw A C, Parton R, Hooker M J 1976 Loss of protective antigen, histamine-sensitising factor and envelope polypeptides in cultural variants of Bordetella pertussis. Journal of Medical Microbiology 9:89-100.

Weiss A A, Falkow S 1984 Genetic analysis of phase change in Bordetella pertussis. Infection and Immunity 43:263-269.

Weiss A A, Hewlett E L, Myers G A, Falkow S 1983 Tn5induced mutations affecting virulence factors of Bordetella pertussis. Infection and Immunity 42:33-41.

Weiss A A, Hewlett E L, Myers G A, Falkow S 1984 Pertussis toxin and extracytoplasmic adenylate cyclase as virulence factors of Bordetella pertussis. Journal of Infectious Diseases 150:219-222. 